\title{
Sutterella stercoricanis sp. nov., isolated from canine faeces
}

\author{
Hazel L. Greetham, ${ }^{1}$ Matthew D. Collins, ${ }^{1}$ Glenn R. Gibson, ${ }^{1}$ \\ Catriona Giffard, ${ }^{2}$ Enevold Falsen ${ }^{3}$ and Paul A. Lawson ${ }^{1}$ \\ ${ }^{1}$ Food Microbial Sciences Unit, School of Food Biosciences, University of Reading, \\ Reading RG6 6AP, UK \\ ${ }^{2}$ Waltham Centre for Pet Nutrition, Waltham-on-Wolds, Melton Mowbray LE14 4RT, UK \\ ${ }^{3}$ Culture Collection, Department of Clinical Microbiology, University of Göteborg, SE-413 46 \\ Göteborg, Sweden
}

\begin{abstract}
Morphological, biochemical and molecular genetic studies were carried out on an unknown non-spore-forming, Gram-negative, rod-shaped bacterium which was isolated from dog faeces. The bacterium grew under anaerobic conditions, was asaccharolytic, resistant to $20 \%$ (v/v) bile and was oxidase- and urease-negative. Phylogenetic analysis based on comparative 16S rRNA gene sequencing showed that the unidentified bacterium clustered with Sutterella wadsworthensis, although a sequence divergence of $>5 \%$ indicated that the bacterium from dog faeces represented a previously unrecognized subline within the genus. On the basis of the presented findings, a novel species, Sutterella stercoricanis sp. nov., is described. The type strain of Sutterella stercoricanis is $5 B A C 4^{\top}\left(=\right.$ CCUG $47620^{\top}=$ CIP $\left.108024^{\top}\right)$.
\end{abstract}

The genus Sutterella was proposed by Wexler et al. (1996) to accommodate some Campylobacter gracilis-like organisms from human clinical sources. The organisms consisted of bile-resistant, asaccharolytic, nitrate-positive, ureasenegative, Gram-negative rods that were phenotypically and genotypically distinct from Campylobacter (formerly Bacteroides) gracilis. Currently, only a single species of the genus Sutterella is known, namely Sutterella wadsworthensis (Wexler et al., 1996). The genus Sutterella belongs in the family Alcaligenaceae within the $\beta$-Proteobacteria. To date, $S$. wadsworthensis has been isolated from patients with a variety of gastrointestinal infections (Wexler et al., 1996), and there is evidence (Engberg et al., 2000) that it occurs in human faeces. During the course of a study on taxonomically problematic organisms within the canine gut, we have characterized an unusual Gram-negative, short, rodshaped organism from faeces which phenotypically resembles the genus Sutterella. In this article, we report the phenotypic characteristics of this Sutterella-like organism and the results of a phylogenetic study. On the basis of the presented findings, we propose that the unknown organism be designated a novel species of the genus Sutterella, for which the name Sutterella stercoricanis sp. nov. is proposed.

Strain $5 \mathrm{BAC} 4^{\mathrm{T}}$ was isolated from the faeces of a healthy male Labrador dog. Faecal samples were collected immediately following defecation and used to prepare a $10 \%(\mathrm{w} / \mathrm{v})$

The GenBank/EMBL/DDBJ accession number for the 16S rRNA gene sequence of strain CCUG $47620^{\top}$ is AJ566849. slurry using pre-reduced $0 \cdot 1 \mathrm{M}$ PBS (pH 7). The slurry was transferred into an anaerobic cabinet $\left(10 \% \mathrm{H}_{2}, 10 \% \mathrm{CO}_{2}\right.$, $80 \% \mathrm{~N}_{2}$ ) and homogenized for $10 \mathrm{~min}$. Serial 10-fold dilutions were prepared using half-strength peptone water and cysteine hydrochloride $\left(0 \cdot 5 \mathrm{~g} \mathrm{l}^{-1}\right)$. Strain $5 \mathrm{BAC} 4^{\mathrm{T}}$ was isolated from bacteroides agar (Holdeman et al., 1977) that had been incubated at $37^{\circ} \mathrm{C}$ for $48 \mathrm{~h}$, from a $10^{-5}$ dilution. The organism was isolated from two out of five faecal samples examined (counts of $4 \cdot 8$ and $5 \cdot 7 \log _{10}$ c.f.u. $\mathrm{g}^{-1}$ ). Haemolysis was tested on anaerobic blood agar (Oxoid). Cellular morphology and motility were examined in peptone/yeast extract/glucose broth and from anaerobic blood agar. Aerotolerance was determined by incubating the organism on brucella agar plates with and without $5 \%(\mathrm{v} / \mathrm{v})$ laked sheep blood in an atmosphere containing either 2 or $6 \%$ oxygen, as described by Wexler et al. (1996). Traditional biochemical tests were performed as described by Holdeman et al. (1977). The oxidase test was performed as described by Summanen et al. (1993). Urease activity was determined using urease discs (Rosco Diagnostics). Biochemical tests were also carried out using the commercially available API Rapid ID 32A and API ZYM systems (bioMérieux) according to the manufacturer's instructions. Long-chain cellular fatty acids were analysed by the MIDI system (Microbial ID). For the determination of $\mathrm{G}+\mathrm{C}$ content, DNA was isolated after disruption of cells using a French pressure cell and then purified in hydroxyapatite. The $\mathrm{G}+\mathrm{C}$ content (mol\%) was determined by using HPLC after digestion of DNA with P1 nuclease and alkaline phosphatase, as described by Mesbah et al. (1989). DNA-DNA 
reassociation experiments were carried out according to the spectrophotometric method of De Ley et al. (1970), with the modification described by Huß et al. (1983) and Escara \& Hutton (1980) using a Gilford System model 2600 spectrometer equipped with a Gilford model 2527-R thermoprogrammer and plotter. The 16S rRNA genes of the isolate were amplified by a PCR using universal primers $\mathrm{pA}$ (positions 8-28, Escherichia coli numbering) and $\mathrm{pH}^{*}$ (positions 1542-1522). The amplified product was purified using a QIAquick PCR purification kit (Qiagen) and directly sequenced using primers directed towards conserved positions of the rRNA gene, the dRhodamine terminator cycle sequencing kit (PE Applied Biosystems) and an automatic DNA sequencer (model 377; PE Applied Biosystems). The closest known relatives of the new isolate were determined by performing database searches using the program FASTA (Pearson \& Lipman, 1985). Closely related sequences were retrieved from EMBL and aligned with the newly determined sequence using the program SEQtools (Rasmussen, 2002). The resulting multiple sequence alignment had approximately 100 bases at the $5^{\prime}$ end of the rRNA omitted from further analysis, because of alignment uncertainties due to the highly variable region V1, using the program GeneDoc (Nicholas et al., 1997). A phylogenetic tree was reconstructed according to the neighbour-joining method with the programs SEQtools and TREEVIEW (Page, 1996) and the stability of the groupings was estimated by bootstrap analysis (1000 replications) using the same programs.
The faecal isolate consisted of non-spore-forming, short, rod-shaped cells. Typical cells were $0.8 \mu \mathrm{m}$ wide and $1 \cdot 5-2 \cdot 0 \mu \mathrm{m}$ in length. The organism grew under anaerobic conditions and in the presence of $2 \%$ oxygen, but not in oxygen at $6 \%$ or more. It was catalase- and oxidase-negative and asaccharolytic in traditional and API test systems. In the commercially available API Rapid ID 32A and API ZYM test systems, the unidentified isolate was very unreactive; apart from a weak activity for glycine arylamidase all other tests were negative. The long-chain cellular fatty acids consisted of 3-OH C $12: 0(2 \cdot 2 \%)$, iso-2-OH $\mathrm{C}_{13: 0}$, $(0 \cdot 6 \%), \mathrm{C}_{14: 0}(9 \cdot 1 \%)$, iso- $\mathrm{C}_{14: 0}(2 \cdot 2 \%)$, iso- $\mathrm{C}_{15: 0}(1 \cdot 3 \%)$, $\mathrm{C}_{16: 0}(42 \cdot 1 \%), \mathrm{C}_{16: 1} \operatorname{cis} 9(16 \cdot 7 \%), \mathrm{C}_{18: 0}(6 \cdot 1 \%), \mathrm{C}_{18: 1}$ cis 9 $(13 \cdot 6 \%)$ and $\mathrm{C}_{18: 1}$ cis $11(6 \cdot 4 \%)$. To ascertain the phylogenetic position of the unknown organism, comparative $16 \mathrm{~S}$ rRNA gene sequencing was carried out. The almost complete sequence ( $>1400 \mathrm{nt}$ ) of the 16S rRNA gene of the isolate was determined. Sequence database searches revealed highest sequence relatedness to $S$. wadsworthensis ( $94.7 \%$ sequence similarity); other taxa (e.g. Achromobacter, Alcaligenes and Bordetella species, Leptothrix discophora) were more distantly related (data not shown). Treeing analysis confirmed that the unknown dog-gut bacterium was phylogenetically most closely associated with S. wadsworthensis (Fig. 1). DNA-DNA reassociation was conducted between the unknown strain, $5 \mathrm{BAC} 4^{\mathrm{T}}$, and $S$. wadsworthensis CCUG $42229^{\mathrm{T}}$. The two strains displayed $35 \%$ DNA relatedness, consistent with separate species status.

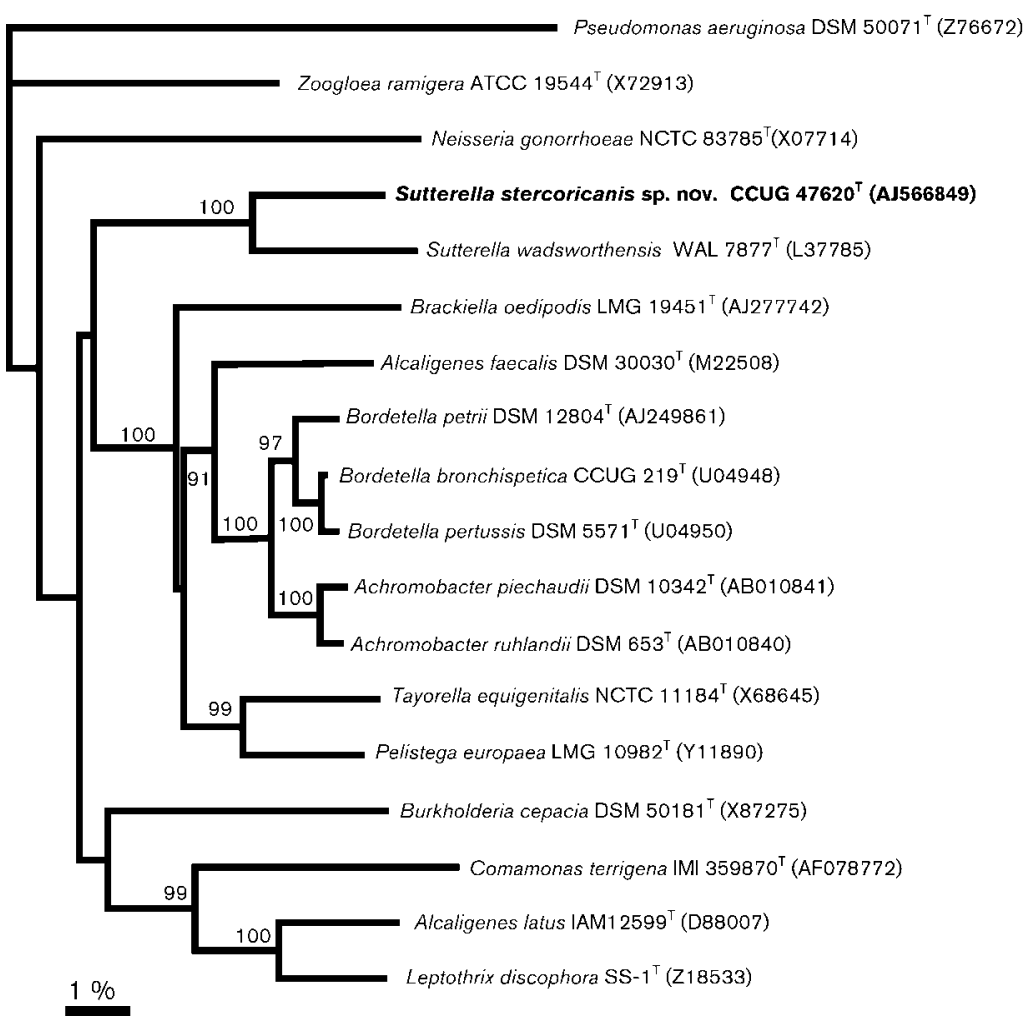

Fig. 1. Unrooted tree showing the phylogenetic relationships of $S$. stercoricanis sp. nov. and its close relatives. The tree, constructed using the neighbour-joining method, was based on a comparison of approximately $1300 \mathrm{nt}$. Bootstrap values expressed as a percentage of 1000 replications are given at the branching points. 
It is evident from the results of the taxonomic study that the Gram-negative, rod-shaped isolate recovered from dog faeces represents a hitherto unknown species. Phylogenetically, the novel organism displayed a statistically highly significant association with $S$. wadsworthensis, the clustering together of these organisms being supported by a bootstrap resampling value of $100 \%$ (Fig. 1). The affinity between the dog bacterium and $S$. wadsworthensis was strongly supported in terms of phenotypic criteria. In particular, the dog bacterium closely resembled the genus Sutterella in being asaccharolytic, oxidase-negative, ureasenegative, bile-resistant and nitrate-positive. Further support for the close association between the unidentified organism and S. wadsworthensis was evident from long-chain cellular fatty acid data, the major fatty acids being $\mathrm{C}_{14: 0}$, $\mathrm{C}_{16: 0}, \mathrm{C}_{16: 1}$ cis 9 and $\mathrm{C}_{18: 1}$ cis 9 .

Although clustering of the unknown dog bacterium with S. wadsworthensis was statistically significant, a sequence divergence of $>5 \%$ between these taxa indicated that the relationship was not particularly close. While there is no precise cut-off for delineating species based on sequence divergence values alone, it is universally recognized that divergence values of $3 \%$ or more indicate that organisms are not related at the species level (Stackebrandt \& Goebel, 1994). The observed 16S rRNA gene divergence value between the unknown dog bacterium and S. wadsworthensis clearly demonstrates that these organisms represent closely related, albeit different, genetic species. This result was confirmed by DNA-DNA reassociation which demonstrated that the novel isolate and S. wadsworthensis represent different genospecies. Therefore, on the basis of the presented findings we propose that the unknown rod-shaped organism from dog faeces be assigned to the genus Sutterella as a novel species, Sutterella stercoricanis sp. nov. S. stercoricanis phenotypically closely resembles $S$. wadsworthensis, but can be distinguished from the latter by its negative leucine arylamidase, arginine arylamidase and alkaline phosphatase reactions in the API Rapid ID 32A test system. Although only a single strain of $S$. stercoricanis is currently known, we consider that the formal description of this species, together with $16 \mathrm{~S}$ rRNA gene sequence data and biochemical criteria to aid its identification, will facilitate its recognition in the routine laboratory, thereby permitting the recovery of additional strains.

\section{Description of Sutterella stercoricanis sp. nov.}

Sutterella stercoricanis (ster.co.ri.ca'nis. L. n. stercus, -oris faeces; L. gen. n. canis of the dog; N.L. gen. n. stercoricanis from dog faeces).

Cells consist of short, straight rods, approximately $0 \cdot 8 \times 1 \cdot 5-2 \mu \mathrm{m}$, which stain Gram-negative. No spores are observed. Non-haemolytic. Grows under anaerobic and microaerophilic conditions, growing in $2 \%$, but not $6 \%$, oxygen. Resistant to $20 \%(\mathrm{v} / \mathrm{v})$ bile. Oxidase- and catalasenegative. Nitrate is reduced. Asaccharolytic. Using the commercially available API test systems, no activity is detected for acid phosphatase, alkaline phosphatase, alanine arylamidase, $\alpha$-arabinosidase, arginine arylamidase, arginine dihydrolase, esterase $\mathrm{C} 4$, ester lipase $\mathrm{C} 8, \alpha$-chymotrypsin, cystine arylamidase, $\alpha$-fucosidase, $\alpha$-glucosidase, $\beta$-glucosidase, $\beta$-glucuronidase, $\alpha$-galactosidase, $\beta$-galactosidase, $\beta$ galactosidase-6-phosphate, glutamic acid decarboxylase, glutamyl glutamic acid arylamidase, histidine arylamidase, leucine arylamidase, leucyl glycine arylamidase, lipase C14, $\alpha$-mannosidase, $N$-acetyl- $\beta$-glucosaminidase, proline arylamidase, phenylalanine arylamidase, phosphoamidase, pyroglutamic acid arylamidase, serine arylamidase, trypsin, valine arylamidase, urease or tyrosine arylamidase. Weak activity for glycine arylamidase may be detected. Indole is not produced. The long-chain cellular fatty acids are mainly of the straight-chain saturated and monounsaturated types, with $\mathrm{C}_{14: 0}, \mathrm{C}_{16: 0}, \mathrm{C}_{16: 1}$ and $\mathrm{C}_{18: 1}$ predominating.

The type strain is $5 \mathrm{BAC}^{\mathrm{T}} \quad\left(=\mathrm{CCUG} \quad 47620^{\mathrm{T}}=\mathrm{CIP}\right.$ $\left.108024^{\mathrm{T}}\right)$. The $\mathrm{G}+\mathrm{C}$ content of DNA of the type strain is $60 \mathrm{~mol} \%$. Isolated from faeces of a healthy male Labrador dog.

\section{Acknowledgements}

H. L. G. was in receipt of a BBSRC Case studentship with the Waltham Centre for Pet Nutrition.

\section{References}

De Ley, J., Cattoir, H. \& Reynaerts, A. (1970). The quantitative measurements of DNA hybridization from renaturation rates. Eur J Biochem 12, 133-142.

Engberg, J., On, S. L., Harrington, C. S. \& Gerner-Smidt, P. (2000). Prevalence of Campylobacter, Arcobacter, Helicobacter, and Sutterella spp. in human fecal samples as estimated by a reevaluation of isolation methods for campylobacters. J Clin Microbiol 38, 286-291.

Escara, J. F. \& Hutton, J. R. (1980). Thermal stability and renaturation of DNA in dimethyl sulfoxide solutions: acceleration of the renaturation rate. Biopolymers 19, 1315-1327.

Holdeman, L. V., Cato, E. P. \& Moore, W. E. C. (1977). Anaerobe Laboratory Manual, 4th edn. Blacksburg, VA: Virginia Polytechnic Institute and State University.

Huß, V. A. R., Festl, H. \& Schleifer, K. H. (1983). Studies on the spectrometric determination of DNA hybridization from renaturation rates. Syst Appl Microbiol 4, 184-192.

Mesbah, M., Premachandran, U. \& Whitman, W. B. (1989). Precise measurement of the $\mathrm{G}+\mathrm{C}$ content of deoxyribonucleic acid by high performance liquid chromatography. Int J Syst Bacteriol 39, 159-167.

Nicholas, K. B., Nicholas, H. B., Jr \& Deerfield, D. W., II (1997). GeneDoc: analysis and visualization of genetic variation. EMBNEW News 4, 14.

Page, R. D. M. (1996). TREeVIEW: an application to display phylogenetic trees on personal computer. Comput Appl Biosci 12, 357-358.

Pearson, W. R. \& Lipman, D. J. (1985). Rapid and sensitive protein similarity searches. Science 227, 1435-1441.

Rasmussen, S. W. (2002). SEQtools, a software package for analysis of nucleotide and protein sequences. http://www.seqtools.dk

Stackebrandt, E. \& Goebel, B. M. (1994). Taxonomic note: a place for DNA-DNA reassociation and 16S rRNA sequence analysis in the 
present species definition in bacteriology. Int J Syst Bacteriol 44, 846-849.

Summanen, P., Baron, E. J., Citron, D., Strong, C., Wexler, H. M. \& Finegold, S. M. (1993). Wadsworth Anaerobic Bacteriology Manual, 5th edn. Belmont, CA: Star Publishing.
Wexler, H. M., Reeves, D., Summanen, P. H., Molitoris, E., McTeague, M., Duncan, J., Wilson, K. H. \& Finegold, S. M. (1996). Sutterella wadsworthensis gen. nov., sp. nov., bile-resistant microaerophilic Campylobacter gracilis-like clinical isolates. Int J Syst Bacteriol 46, 252-258. 